\title{
Age-dependent kinetics of dentate gyrus neurogenesis in the absence of cyclin D2
}

\author{
Anne Ansorg, Otto W Witte and Anja Urbach ${ }^{*}$
}

\begin{abstract}
Background: Adult neurogenesis continuously adds new neurons to the dentate gyrus and the olfactory bulb. It involves the proliferation and subsequent differentiation of neuronal progenitors, and is thus closely linked to the cell cycle machinery. Cell cycle progression is governed by the successive expression, activation and degradation of regulatory proteins. Among them, D-type cyclins control the exit from the $G_{1}$ phase of the cell cycle. Cyclin D2 (cD2) has been shown to be required for the generation of new neurons in the neurogenic niches of the adult brain. It is differentially expressed during hippocampal development, and adult cD2 knock out (cD2KO) mice virtually lack neurogenesis in the dentate gyrus and olfactory bulb. In the present study we examined the dynamics of postnatal and adult neurogenesis in the dentate gyrus (DG) of CD2KO mice. Animals were injected with bromodeoxyuridine at seven time points during the first 10 months of life and brains were immunohistochemically analyzed for their potential to generate new neurons.
\end{abstract}

Results: Compared to their WT litters, CD2KO mice had considerably reduced numbers of newly born granule cells during the postnatal period, with neurogenesis becoming virtually absent around postnatal day 28. This was paralleled by a reduction in granule cell numbers, in the volume of the granule cell layer as well as in apoptotic cell death. CD2KO mice did not show any of the age-related changes in neurogenesis and granule cell numbers that were seen in WT litters.

Conclusions: The present study suggests that hippocampal neurogenesis becomes increasingly dependent on CD2 during early postnatal development. In CD2KO mice, hippocampal neurogenesis ceases at a time point at which the tertiary germinative matrix stops proliferating, indicating that CD2 becomes an essential requirement for ongoing neurogenesis with the transition from developmental to adult neurogenesis. Our data further support the notion that adult neurogenesis continuously adds new neurons to the hippocampal network, hence increasing cell density of the DG.

\section{Background}

As one of the neurogenic zones in the adult mammalian brain, the hippocampal dentate gyrus (DG) generates neural progenitor-derived neurons throughout life. This process, known as adult neurogenesis, is modulated by various intrinsic and extrinsic factors ranging from neurotransmitters, growth factors, hormones, physical activity, learning, to seizures and other brain pathologies (reviewed in [1]). The newborn neurons have been shown to become functionally integrated into the preexisting neuronal circuitry [2-4]. During the first weeks of life, newborn neurons express unique physiological

\footnotetext{
* Correspondence: anja.urbach@med.uni-jena.de

Hans Berger Department of Neurology, Jena University Hospital, Erlanger Allee 101, 07747 Jena, Germany
}

characteristics thereby providing the network with enhanced functional plasticity [5], extensively reviewed in [6]. Whilst recent research suggests an involvement of newborn granule cells (DGC) in hippocampal function, the precise role of these cells still remains elusive.

Cyclin D2 belongs to a family of three highly homologous D-type cyclins (cyclins D1, 2 and 3) which are important regulators of cell cycle progression. Once activated, D-type cyclins associate with and thereby activate the cyclin-dependent kinases cdk4 and cdk6 $[7,8]$. These cyclin D-cdk complexes are deemed to execute critical functions during middle to late G1 phase and to be essential for the transition from G1 to S-phase [7-9]. Unlike many other cyclins that are expressed periodically during the cell cycle, D-type cyclins become synthesized in response to mitogens and their expression 
rapidly declines when mitogens are withdrawn [10-13]. Mitogenic signalling is also required for assembly and kinase activity of cyclin D-cdk complexes [10]. Consequently, D-type cyclins are regarded as constituting a molecular link between the extracellular environment and the cell cycle machinery.

Although different D-type cyclins can be detected in a particular cell type, they exhibit distinct cell- and tissuespecific expression patterns both during development and in adulthood [13-15]. Studies from knock out mice with deletions of one, two, or all G1 cyclins revealed remarkably normal morphogenesis at least until midgestation (reviewed in [16]), indicating a considerable degree of functional redundancy and compensatory capacity [17-23]. Mice lacking just a single D-type cyclin are viable, exhibiting only narrow, tissue-specific defects. Severe phenotypic abnormalities are observed only in those tissues expressing just one D-type cyclin, which feature no ability to compensate, i.e. by upregulating an alternative D-cyclin [19,22-25].

In the present work we analyzed postnatal and adult hippocampal neurogenesis in mice lacking cD2 (cD2KO). These animals have been reported to exhibit female sterility, hypoplastic testes in males [22], as well as cerebellar abnormalities [24] and impaired proliferation of B-lymphocytes [26]. Importantly, Kowalczyk and coworkers [27] revealed a requirement of $\mathrm{cD} 2$ for adult neurogenesis. They showed that proliferation is impaired in the neurogenic zones of adult cD2KO mice whilst developmental neurogenesis at postnatal day 5 appeared to be close-to normal. The aim of our study was to determine the kinetics of postnatal and adult neurogenesis as well as the precise age at which neurogenesis ceases in the absence of functional cD2. We characterized $\mathrm{cD} 2 \mathrm{KO}$ and WT mice at seven time points during the first 10 months of life, and determined their potential to generate new neurons in the DG.

\section{Results}

In the present study we examined cell proliferation, neurogenesis and morphometric parameters of the hippocampus of $\mathrm{cD} 2 \mathrm{KO}$ and WT litters at seven time points during the first 10 months of life (Figure 1).

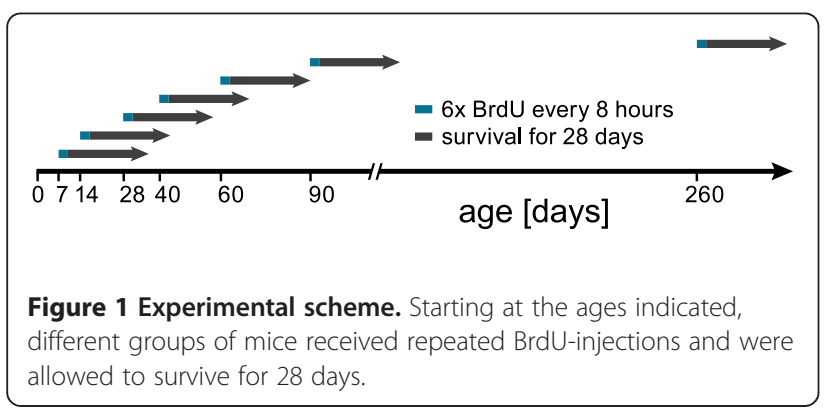

\section{Morphometry}

Volumetric estimation of the entire brain, hippocampus and the dentate GCL in CD2KO mice revealed significant differences compared to WT litters at all ages examined. On average, the brain was smaller by $\sim 26 \%$ (Figures 2 and $3 \mathrm{~A}$ ), the hippocampus by $\sim 31 \%$ (Figure $3 \mathrm{~B}$ ) and the dentate GCL by $\sim 49 \%$ (Figure $3 \mathrm{C}$ ). These differences were already present in 1 month-old animals (P7 group). In both genotypes, brain volume remained fairly constant over time (Figure 3A). We only detected a slight increase from P35 to P118 $(p=0.011)$ and P88 to P288 $(p=0.018)$ in WT mice, and from P42 to P68 $(p=0.007)$ and P42 to P288 ( $p=0.029)$ in cD2KO mice. The volume of the HC increased continuously in WT mice, especially when comparing ages of P88 and younger to P288 (P88 vs. P288: $p=0.042$; Figure 3B). In contrast, the $\mathrm{HC}$ volume of $\mathrm{cD} 2 \mathrm{KO}$ mice showed no significant age-related differences. Similarly, the dentate GCL volume did not change with increasing age, independent of genotype (Figure 3C).

Although cD2KO mice tended to have lower body weights than WT litters, the only significant difference was observed in mutant mice at P288 with about $14 \%$ less body weight ( $p=0.018$; Figure 3D).

\section{Absolute number of dentate granule cells}

The total number of DGCs in adult animals differed significantly between WT and $\mathrm{cD} 2 \mathrm{KO}$ mice (Figure 4). At P88, cD2KO mice had $\sim 60 \%$ fewer DGCs than their WT litters (WT: $1006057 \pm 79843$, cD2KO: $406455 \pm 28201$; $\mathrm{p}<0.001)$. At P288, the number of DGCs in $\mathrm{cD} 2 \mathrm{KO}$ mice was $\sim 65 \%$ lower as compared to WT mice (WT: $1179307 \pm 36738$, cD2KO: $409150 \pm 35489 ; \mathrm{p}<0.001)$. Moreover, the number of DGCs in WT, but not in cD2KO mice, increased between P88 and P288 $(\mathrm{p}=0.032)$. For all animals the CE fell below 0.05 .

\section{Number of BrdU-positive cells}

BrdU was injected in WT and $\mathrm{CD} 2 \mathrm{KO}$ mice of different ages (6 times at 8-hour intervals starting either at postnatal day (P)7, P14, P28, P40, P60, P90 or P260). The brains of these animals were examined 28 days later (Figure 1). BrdU-positive cell numbers were significantly reduced in the DG of cD2KO mice $(p<0.001)$, an effect that could be observed at all ages analyzed in this study (Figures 5 and 6). The difference was lowest at early postnatal ages with about $60 \%$ less BrdU-positive cells in cD2KO mice compared to WT litters (P7 and P14, $p$ $<0.002$ ). As early as in the P28 group the difference between $\mathrm{cD} 2 \mathrm{KO}$ and WT mice reached $>93 \%(p<0.001)$, with very scarce BrdU-positive cells in the DG of $\mathrm{cD} 2 \mathrm{KO}$ animals. In both genotypes, age significantly affected BrdU-positive cell numbers, with changes fitting best to a power function (WT: $f(\mathrm{x})=668654 \mathrm{x}^{-1.3727}, \mathrm{R}^{2}=0.9794$; 


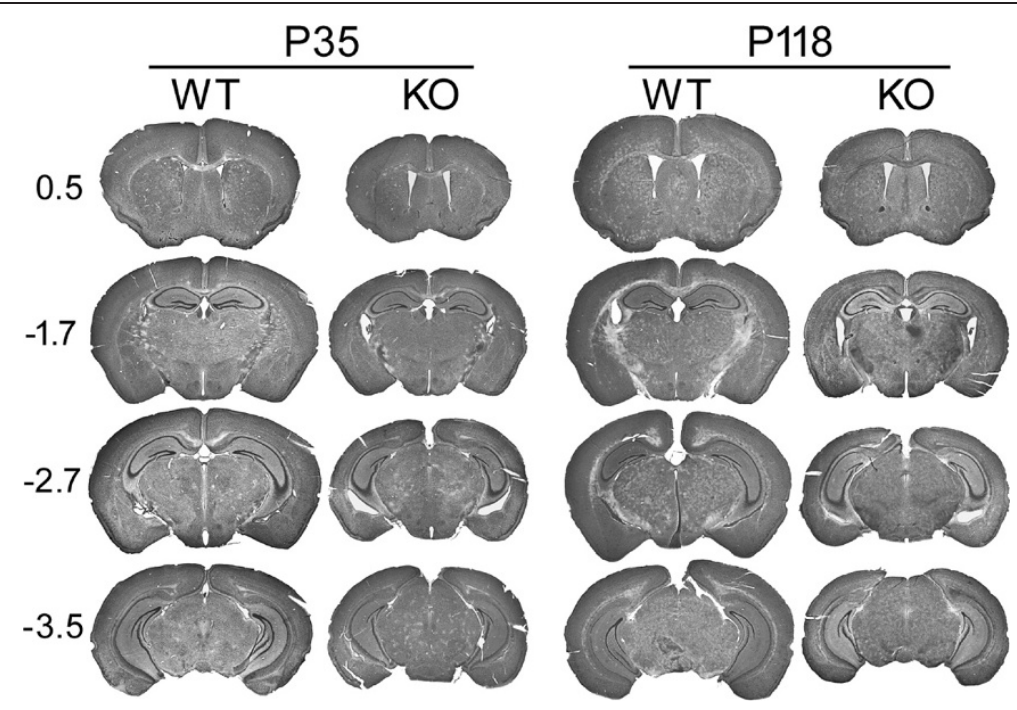

Figure 2 Examples of Nissl-stained sections spanning the rostro-caudal axis of the brain illustrating differences in overall brain structure of WT and CD2KO mice. Positions relative to bregma are marked on the left. The gross morphology of cD2KO brains appears to be close to normal but brains of cD2KO mice are smaller than that of their WT litters. Size differences are already apparent at P35.

cD2KO: $\left.f(\mathrm{x})=461772 \mathrm{x}^{-1.8231}, \mathrm{R}^{2}=0.9288\right)$. BrdU-incorporation was highest in the P7 brain and subsequently declined with increasing age. The dynamic of the agerelated decline in BrdU-positive cell numbers was slightly different in $\mathrm{cD} 2 \mathrm{KO}$ and $\mathrm{WT}$ mice. In $\mathrm{cD} 2 \mathrm{KO}$ mice, newborn cell numbers decreased by $\sim 75 \%$ between P7 and P14 $(p<0.001)$ and further between P14 and P28 ( 93\%, $p$ $<0.001)$. As early as at P28, BrdU-positive cells were virtually absent in these animals, with their numbers remaining roughly stable until P90, followed by a further decline towards P260 $(\sim 87 \%, p<0.001)$. In contrast, WT mice started with a much higher level of cell birth (P7) and newborn cell numbers declined continuously during adulthood (Figure 6). Between P7 and P14, newborn cell numbers declined at a similar rate than in $\mathrm{cD} 2 \mathrm{KO}(\sim 79 \%$, $p<0.001)$, while the subsequent decrease was less
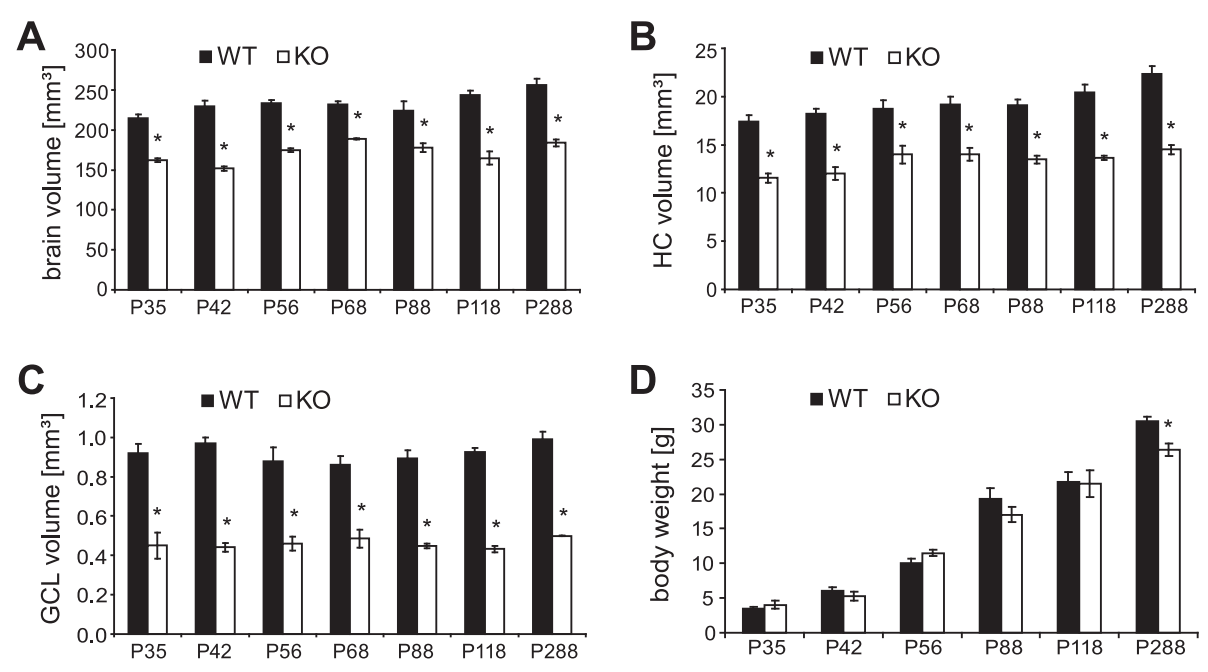

Figure 3 Differences in brain structure and body weight of WT and CD2KO mice. Estimations of the total (bilateral) volume of brain (A) hippocampus (B) and the dentate $\mathrm{GCL}(\mathbf{C})$ reveal substantial reduction of these structures due to the lack of functional $\mathrm{CD} 2\left(^{*} p<0.001\right)$. Differences are already apparent at P35. (D) The body weight of CD2KO mice is similar to that of WT litters, except at an age of P288 $\left(^{*} p<0.01\right)$. Statistical significance is only marked for genotype-specific differences. 


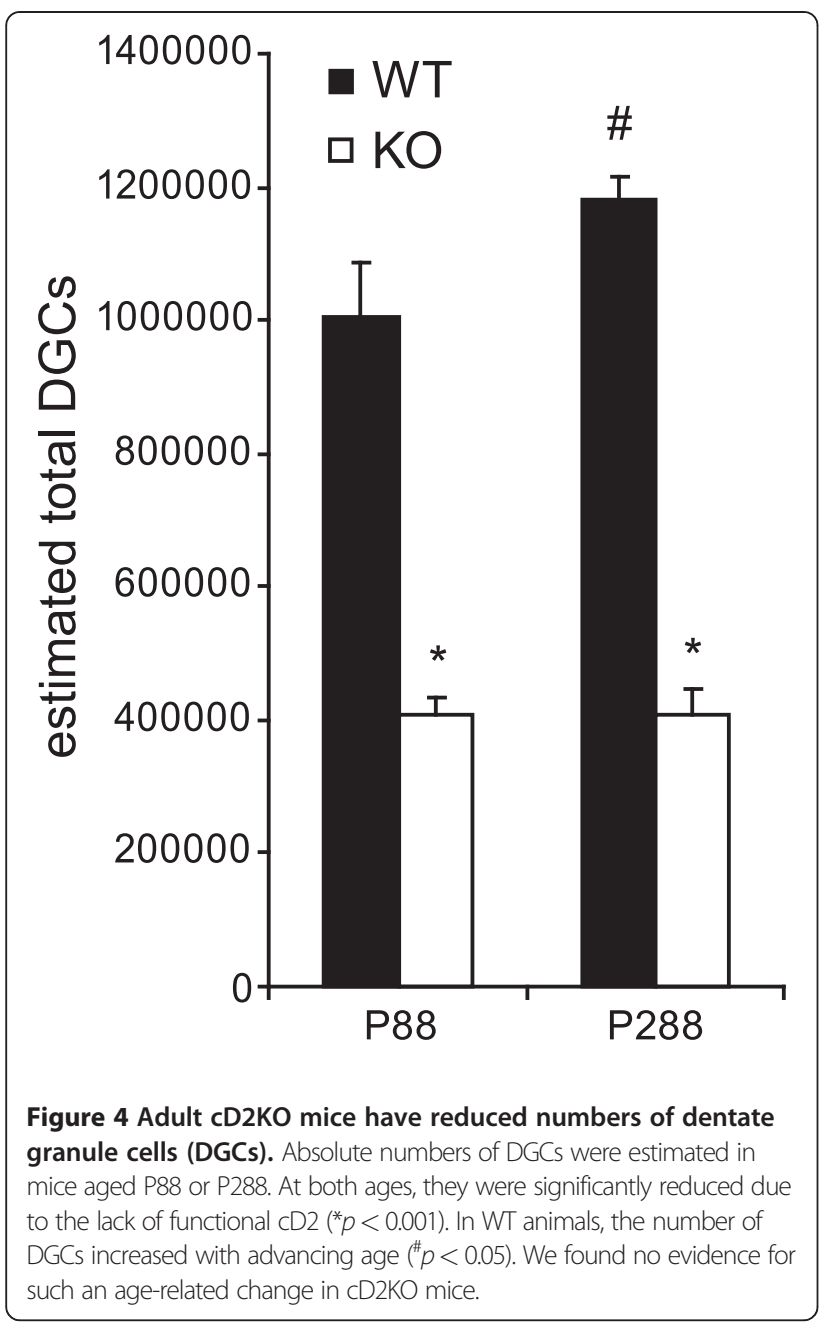

pronounced $(\sim 72 \%$ between P14 and P40, $p=0.001)$. BrdU-positive cell numbers continued to decline in WT by $\sim 68 \%$ between P28 and P90 $(p=0.002)$, and by $~ 83 \%$ between P90 and P260 ( $p<0.001)$.

Independent of genotype and age, BrdU-positive nuclei appeared preferentially in the subgranular layer (SGZ) and inner GCL (Figure 5). However, on BrdU being injected at ages $\leq$ P14, BrdU-positive cells also appeared scattered throughout the hilus and, in particular in the P7 group, in the molecular layer and other parts of the developing $\mathrm{HC}$ (Figure 5).

\section{Phenotype of BrdU-positive cells}

To determine the potential of DG progenitor cells to differentiate into neurons we stained coronal sections against BrdU, GFAP and NeuN so as to distinguish astrocytes and putative stem cells (both expressing GFAP) from neurons (expressing NeuN; Figure 7A). Independent of genotype and age of the animals, BrdU-labeled progenitors preferentially differentiated into neurons within 4 weeks (on average $62 \%$ in WT and $57 \%$ in $\mathrm{CD} 2 \mathrm{KO}$; Table 1), indicating that neuronal differentiation is not affected by the lack of functional $\mathrm{cD} 2$. Only a small percentage (on average $5 \%$ in both genotypes; Table 1) of newborn cells expressed GFAP leaving about $35 \%$ of BrdU-positive cells with an unidentifiable phenotype (not co-localized to either NeuN or GFAP). However, when extrapolated to absolute numbers, the lack of functional $\mathrm{cD} 2$ resulted in a significant reduction of the number of adult-born dentate granule neurons. Genotype and age-related differences in absolute numbers of newborn neurons were similar to those observed in BrdU-positive cell counts (Table 1). For example, in the cD2KO group we found 261 new neurons that were born at P28/P29, which was $\sim 94 \%$ less than in corresponding WT litters.

Proliferating (Ki67-positive) cells and co-labeling with DCX To evaluate the number of cells with ongoing proliferation, we stained brain sections of $\mathrm{WT}$ and $\mathrm{CD} 2 \mathrm{KO}$ mice killed at P35, P88, or P288 (P7, P60, and P260 group, respectively) against Ki67, a nuclear antigen that is expressed during the $G_{1}, S, M$ and $G_{2}$ phases of cell cycle. Ki67-positive cells were located as clusters predominantly in the SGZ, irrespective of age or genotype. Quantification revealed that the number of proliferating cells was considerably reduced in cD2KO mice $(p<0.001$; Table 2$)$. Additionally, Ki67-positive cell numbers were highest in the adolescent DG and declined significantly with age in both genotypes $(p<0.05$; Table 2$)$.

To analyze the fraction of proliferating cells that are already determined to the neuronal lineage, we performed co-labeling against $\mathrm{Ki} 67$ and doublecortin (DCX), which serves as marker of putative neuronal progenitors and immature neurons. The fraction and absolute numbers of Ki67-positive cells that co-expressed DCX was considerably reduced in cD2KO mice (Table 2). In WT animals, $\sim 25 \%$ of proliferating Ki67-positive cells were DCX-positive, irrespective of the age of the animals, whilst in cD2KO mice, $9 \%$ of Ki67-positive cells co-expressed DCX (Table 2). At P288, we detected only sparse proliferating cells in $\mathrm{cD} 2 \mathrm{KO}$ mice; cells clearly immunoreactive for DCX were virtually absent (Table 2, Figure $7 \mathrm{~B})$. In general, $\mathrm{cD} 2 \mathrm{KO}$ mice appeared to have less DCX-positive cells than WT litters (Figure 7B).

\section{Number of TUNEL-positive nuclei}

TUNEL-positive, apoptotic cells were only rarely detected in the DG. A significantly lower number of apoptotic cells was observed in $\mathrm{cD} 2 \mathrm{KO}$ compared to WT mice at P35 (WT: $830 \pm 105, \mathrm{cD} 2 \mathrm{KO}: 48 \pm 24$; $p<0.001$; Figure 8). This difference was still present at P88, albeit not statistically significant (WT: $282 \pm 25$, cD2KO: $24 \pm 14 ; p=0.1$; Figure 8 ). A significant decline of TUNEL-positive nuclei was detected between P35 and P88 in WT animals $(p<0.001)$, but not in $\mathrm{cD} 2 \mathrm{KO}$ mice. Independent of genotype or age, TUNELpositive nuclei appeared preferentially in the SGZ. 


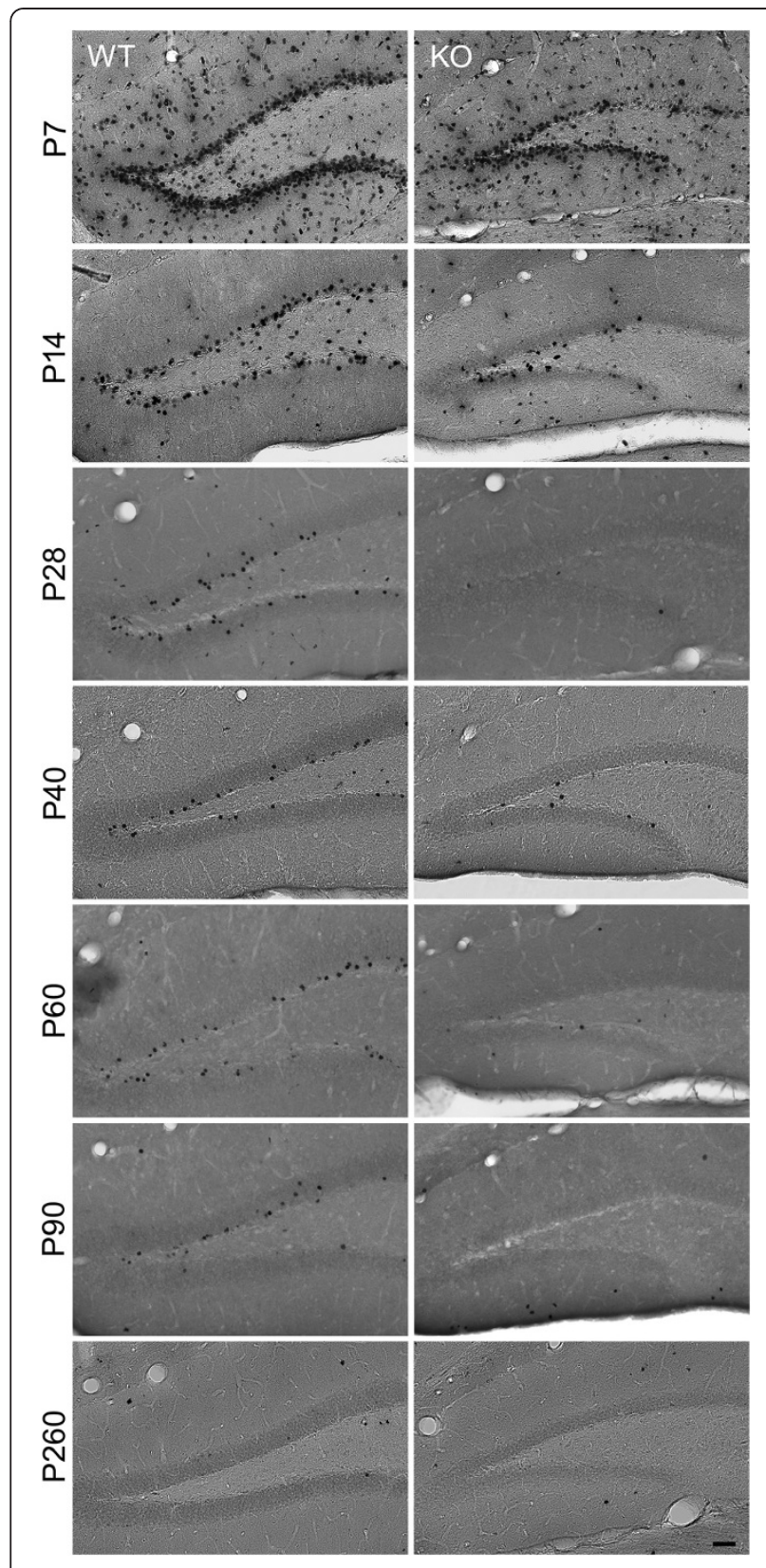

Figure 5 Representative images of BrdU-immunolabeled coronal sections through the DG of CD2KO and WT mice. BrdU-positive nuclei appear almost exclusively in the SGZ and GCL of mice that were BrdUinjected at P14 or later. When BrdU was injected at P7, many BrdU-positive cells were furthermore found scattered through the hilus and molecular layer of the DG. All slices represent approximately the same position in the rostrocaudal extension of the $\mathrm{HC}$, the age of first $\mathrm{BrdU}$ injection is indicated on the left. Scale bar: $50 \mu \mathrm{m}$.

\section{Discussion}

Mice with targeted disruption of the cyclin D2 gene (cD2KO) have been reported to lack newborn neurons in the adult DG and olfactory bulb [27], an attribute making them a useful model to study the function of adult hippocampal neurogenesis. The temporal dependency of neurogenesis on $\mathrm{cD} 2$ during postnatal life has not been clearly evaluated. Hence, we systematically investigated the time course of neurogenesis in the DG of $\mathrm{cD} 2 \mathrm{KO}$ mice by analyzing $\mathrm{cD} 2 \mathrm{KO}$ and WT litters at seven time points during the first 10 months of life for their potential to generate new neurons in the DG. In brief, our results reveal that in cD2KO mice: 1) newborn cell numbers and hippocampal neurogenesis are significantly reduced, 2) neurogenesis virtually ceases at an age around P28, 3) morphology of the hippocampus is almost normal but it is smaller in size, 4) the GCL volume as well as DGC numbers are significantly reduced, 5) the lack of functional $\mathrm{cD} 2$ prevents the age-related increase in DGC numbers, and 6) apoptosis is substantially diminished compared to WT litters.

Adult neurogenesis persists throughout life, both in the SGZ of the hippocampus and in the SVZ/olfactory bulb, however, the potential to generate new neurons substantially declines with increasing age [28-34]. Using the exogenous marker BrdU and the endogenously expressed marker Ki67 to label and detect dividing cells, together with neuronal markers (NeuN and DCX), we confirmed the age-dependent change of adult neurogenesis in both, WT and cD2KO mice. Analyses of WT brains with Ki67 and BrdU revealed that the number of newborn cells declines by about $74 \%$ to $85 \%$, respectively, between the ages of 3 to $9-10$ months. This was paralleled by a decrease in the number of newborn neurons by $87 \%$. The observed rates of age-related changes in cell proliferation are consistent with previous reports studying $\mathrm{C} 57 \mathrm{Bl} / 6$ mice $[29,35]$. Differences in the percentages of Ki67- and BrdU-positive cell numbers in the present study may derive from the distinct characteristics of these markers [36,37] and the labeling protocol applied. Ki67 labels cells during all active phases of the cell cycle $\left(G_{1}, S, G_{2}\right.$, and mitosis) and thus provides a snap shot of the proliferative situation at the time of sacrifice of the animal. The thymidine analogue BrdU is integrated into the DNA of cells during S-phase of cell cycle and retained in the progeny of dividing cells. It is to note, that the results obtained with the labeling scheme used in our study reflect a combination of proliferation and survival.

Noteworthy, we detected a substantial change in the absolute values of cell birth and neurogenesis due to the lack of functional cD2 at all time points analyzed. Whilst postnatal neurogenesis was still present in the DG of cD2KO mice, albeit at a lower level than in WT litters, adult-born neurons were rarely detectable. BrdU incorporation and neurogenesis were virtually absent as early as at P28. These data indicate that postnatal neurogenesis is controlled by $\mathrm{cD} 2$ together with at least one other D-type cyclin, and that the age at which DG neurogenesis becomes exclusively dependent on the expression of functional cD2 lies between P14 and P28. 


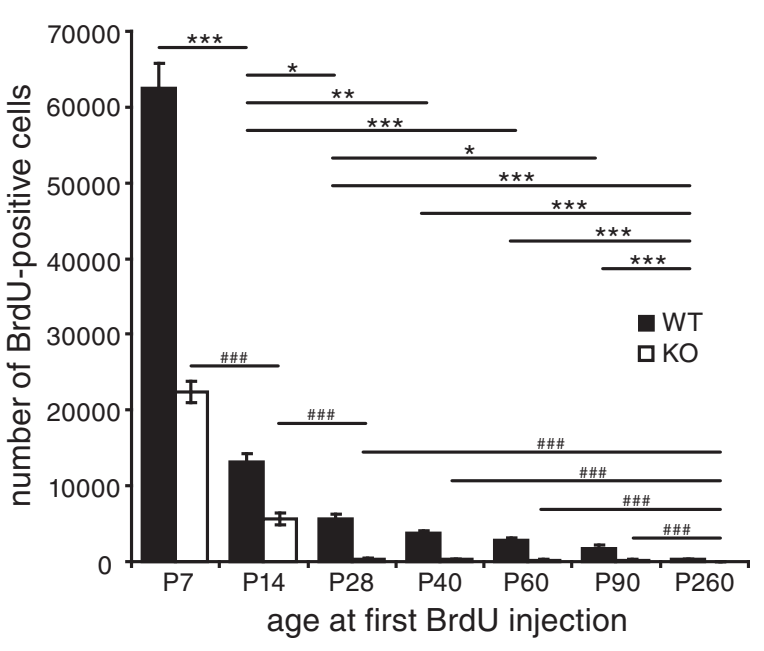

Figure 6 BrdU-positive cell numbers are significantly reduced in CD2KO mice. As compared to WT litters BrdU incorporation is significantly reduced in CD2KO mice at all postnatal ages analyzed $(p<0.001)$. CD2KO animals aged P7 at first BrdU injection have already 60\% reduced BrdU-positive cell numbers as compared to WT litters. As early as P28, newborn cells are almost completely absent in cD2KO mice. In both genotypes, BrdU-positive cell numbers continuously decline during adolescence and adulthood. Statistical differences are only indicated for agedependent changes within WT $\left(^{*}\right)$ and $\mathrm{CD} 2 \mathrm{KO}\left({ }^{*}\right)$ groups $\left({ }^{*} p<0.05,{ }^{* *} p<0.01,{ }^{* * *}\right.$ or ${ }^{\# \# \#} p<0.001$; statistics on In-transformed values).

Granule neurons of the DG are generated over a prolonged period starting early in embryogenesis (at E10 in mice; [38]) and continuing far into postnatal life $[39,40]$. During this period, germinative zones, containing the precursors of DGCs, arise in a consecutive manner with the primary dentate neuroepithelium lining the lateral ventricles arising first, giving rise to the adjacent secondary dentate matrix, which, around the time of birth, sends precursor cells towards the dentate anlage, forming the tertiary germinative matrix $[39,41]$. This proliferative zone constitutes the GCL of the DG from birth up to the third postnatal week. Significantly, between P20 and P30, proliferating cells become gradually confined to the SGZ, which serves as source of newly born neurons in the adult DG. This time window precisely correlates to the age at which DG neurogenesis virtually ceases in $\mathrm{cD} 2 \mathrm{KO}$ mice.

Evidence suggests that developmental hippocampal neurogenesis takes place in the presence of at least one other Dtype cyclin that probably compensates for $\mathrm{CD} 2$ deficiency in cD2KO mice. Supportingly, Glickstein et al. [42] demonstrated that cyclin D1 (cD1) and $\mathrm{cD} 2$ are expressed in a widely overlapping fashion in the germinative matrices that generate the DG. Moreover, they observed a successive change from $\mathrm{cD} 1$ towards $\mathrm{cD} 2$ expression in these germinative zones with ongoing developmental progression, suggesting a tendency of neuronal progenitors to become cD2 dependent during late-stage divisions. Thus, $\mathrm{cD} 1$ is most probably either functionally redundant to, or compensates for $\mathrm{cD} 2$ during development of $\mathrm{cD} 2 \mathrm{KO}$ mice.
In addition, Glickstein and coworkers detected a small number of cD1 immunoreactive cells also in the adult SGZ of WT and cD2KO mice [42]. Moreover, these cells were proven to be proliferating by means of BrdU co-labeling. In the present study, we reaffirmed the existence of $\mathrm{cD} 1$ positive cells in the SGZ of adult WT and $\mathrm{CD} 2 \mathrm{KO}$ mice (Additional file 1). Most likely, cD1 expression in a subset of SGZ progenitors is responsible for the few residual newborn neurons found in the $\mathrm{DG}$ of $\mathrm{cD} 2 \mathrm{KO}$ mice. In apparent contradiction to these results, only the $\mathrm{cD} 2$ transcript has been detected in neurospheres derived from the adult WT hippocampus [27]. However, the fact that neurospheres could be derived from the adult hippocampus of $\mathrm{cD} 2 \mathrm{KO}$ mice [27], which furthermore expressed cD1 mRNA, strengthens the hypothesis that $\mathrm{CD} 1$ accounts for $\mathrm{DG}$ neurogenesis in cD2KO mice.

We observed no significant differences in neuronal differentiation when comparing the fraction of NeuN/BrdU double-labeled cells between WT and cD2KO mice. On average, $60 \%$ of the BrdU-labeled cells expressed NeuN after 28 days of differentiation, independent of genotype or age, which was in the range previously reported for mice and rats $[30,43]$. On the other hand, the fraction of actively dividing neuronal precursors (Ki67/DCX double-positive) was considerably reduced in $\mathrm{CD} 2 \mathrm{KO}$ mice. In contrast to the BrdU/NeuN data - this result might be suggestive of differences in neuronal fate choice. However, this is unlikely since there is strong evidence that DCX-positive progenitors are already determined towards the neuronal 


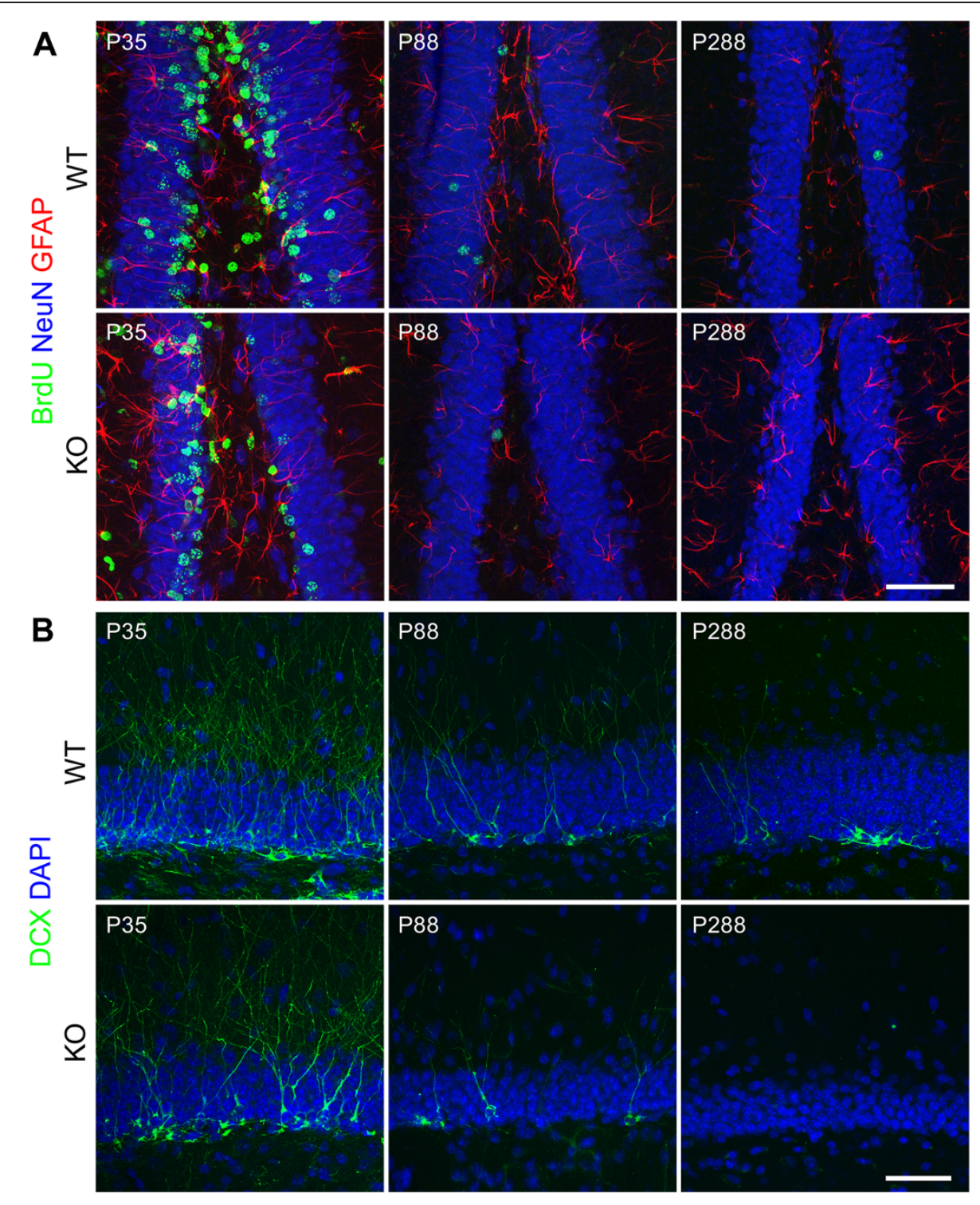

Figure 7 Illustration of neurogenesis in the dentate gyrus of cD2KO and WT litters. (A) Sections of brains aged P35, P88 or P288 were stained against BrdU (green), NeuN (blue) and GFAP (red). Irrespective of genotype, the majority of BrdU-positive cells co-labeled with NeuN indicating that neurogenesis takes place also in the DG of CD2KO mice, albeit at a much lower rate. (B) Representative DCX-labeling (green) at P35, P88 or P288. CD2KO mice appear to have less DCX-positive cells than WT litters. Sections were counterstained with DAPI. The images in (A) and (B) are merges of multiple confocal planes (for NeuN, GFAP, BrdU: 4-5 planes spanning a z-dimension of approximately 4.8 to $6.4 \mu \mathrm{m}$; for DCX: 3-4 planes spanning a z-dimension of approximately 3.6 to $4.8 \mu \mathrm{m})$. Scale bars: $50 \mu \mathrm{m}$.

lineage [44-46]. In the adult dentate gyrus, DCX is expressed by type $2 \mathrm{~b}$ and type 3 progenitors, and by immature neurons [45]. Ki67 has been detected in both, type $2 \mathrm{~b}$ and type 3 cells, denoting that these cells are proliferative [45]. The data of the present study indicate that $\mathrm{CD} 2$ is required for the division of at least a subset of DCX-positive progenitors. Whether these belong to the class of type $2 \mathrm{~b}$ or type 3 transient amplifying cells remains to be determined. An alternative explanation that must be considered as reason for the apparently inconsistent data might be the very low number of dividing cells available for examination of neuronal fate choice in cD2KO mice, which could bias statistical testing.

However, in all groups of WT animals at different ages, $\sim 25 \%$ of all Ki67-positive cells expressed DCX, indicating a stable rate of neuronal differentiation in young adults. These results fit well with previously reported observations in rats [47] and mice [29,45]. 
Table 1 Phenotype of newborn cells 28 days after BrdU delivery

\begin{tabular}{|c|c|c|c|c|c|c|c|c|c|c|c|c|c|c|c|c|c|c|c|}
\hline & & \multicolumn{6}{|c|}{ BrdU } & \multicolumn{6}{|c|}{ NeuN } & \multicolumn{6}{|c|}{ GFAP } \\
\hline & & \multicolumn{3}{|c|}{ WT } & \multicolumn{3}{|c|}{ KO } & \multicolumn{3}{|c|}{ WT } & \multicolumn{3}{|c|}{ KO } & \multicolumn{3}{|c|}{ WT } & \multicolumn{3}{|c|}{ KO } \\
\hline & & mean & \pm & SEM & mean & \pm & SEM & mean & \pm & SEM & mean & \pm & SEM & mean & \pm & SEM & mean & \pm & SEM \\
\hline \multirow[t]{4}{*}{ P7 } & & & $=8$ & & & $(n=$ & & & & & & & & & & & & & \\
\hline & BrdU abs. & 62466.0 & \pm & 3239.3 & 22394.0 & \pm & $1455.3^{* * *}$ & - & \pm & - & - & \pm & - & - & \pm & - & - & \pm & - \\
\hline & $\%$ of BrdU+ & - & \pm & - & - & \pm & - & 57.4 & \pm & 2.0 & 60.7 & \pm & 0.3 & 6.3 & \pm & 1.9 & 4.9 & \pm & 1.2 \\
\hline & abs. co-lab. & - & \pm & - & - & \pm & - & 35621.2 & \pm & 1643.7 & 13593.5 & \pm & $845.7^{* *}$ & 3831.5 & \pm & 1060.3 & 1140.2 & \pm & $336.9^{* *}$ \\
\hline \multirow[t]{4}{*}{ P14 } & & & $=5$ & & & $(n=$ & & & & & & & & & & & & & \\
\hline & BrdU abs. & 13147.2 & \pm & 1060.1 & 5671.5 & \pm & $798.5^{* *}$ & - & \pm & - & - & \pm & - & - & \pm & - & - & \pm & - \\
\hline & $\%$ of $\mathrm{BrdU}+$ & - & \pm & - & - & \pm & - & 64.7 & \pm & 2.2 & 51.0 & \pm & 5.2 & 1.9 & \pm & 1.2 & 1.2 & \pm & 0.8 \\
\hline & abs. co-lab. & - & \pm & - & - & \pm & - & 8480.3 & \pm & 649.6 & 2812.2 & \pm & $271.3^{* *}$ & 223.0 & \pm & 141.4 & 84.3 & \pm & 63.7 \\
\hline \multirow[t]{4}{*}{ P28 } & & & $=4$ & & & $(n=$ & & & & & & & & & & & & & \\
\hline & BrdU abs. & 5578.5 & \pm & 708.4 & 390.0 & \pm & $104.3^{* * *}$ & - & \pm & - & - & \pm & - & - & \pm & - & - & \pm & - \\
\hline & $\%$ of BrdU+ & - & \pm & - & - & \pm & - & 73.1 & \pm & 3.8 & 64.8 & \pm & 2.6 & 0.9 & \pm & 0.1 & 2.6 & \pm & 2.6 \\
\hline & abs. co-lab. & - & \pm & - & - & \pm & - & 4100.7 & \pm & 583.4 & 261.1 & \pm & $88.5^{* * *}$ & 45.8 & \pm & 6.6 & 6.0 & \pm & 6.0 \\
\hline \multirow[t]{4}{*}{ P40 } & & & $=3$ & & & $(n=$ & & & & & & & & & & & & & \\
\hline & BrdU abs. & 3726.0 & \pm & 305.2 & 306.0 & \pm & $51.3^{* * *}$ & - & \pm & - & - & \pm & - & - & \pm & - & - & \pm & - \\
\hline & $\%$ of $\mathrm{BrdU}+$ & - & \pm & - & - & \pm & - & 64.6 & \pm & 4.0 & 60.2 & \pm & 7.1 & 8.3 & \pm & 4.5 & 12.2 & \pm & 6.5 \\
\hline & abs. co-lab. & - & \pm & - & - & \pm & - & 2420.3 & \pm & 299.7 & 190.7 & \pm & $53.1^{* * *}$ & 313.5 & \pm & 186.6 & 31.3 & \pm & 17.0 \\
\hline \multirow[t]{4}{*}{ P60 } & & & $=4$ & & & $(n=$ & & & & & & & & & & & & & \\
\hline & BrdU abs. & 2893.5 & \pm & 205.5 & 222.0 & \pm & $52.7^{* * *}$ & - & \pm & - & - & \pm & - & - & \pm & - & - & \pm & - \\
\hline & $\%$ of $\mathrm{BrdU}+$ & - & \pm & - & - & \pm & - & 60.1 & \pm & 4.1 & 46.3 & \pm & 5.7 & 3.8 & \pm & 2.8 & 0.0 & \pm & 0.0 \\
\hline & abs. co-lab. & - & \pm & - & - & \pm & - & 1756.7 & \pm & 219.8 & 101.3 & \pm & $23.6^{* * *}$ & 94.9 & \pm & 68.6 & 0.0 & \pm & 0.0 \\
\hline \multirow[t]{4}{*}{ P90 } & & & $=4$ & & & $(n=$ & & & & & & & & & & & & & \\
\hline & BrdU abs. & 1770.0 & \pm & 354.2 & 205.5 & \pm & $81.5^{* * *}$ & - & \pm & - & - & \pm & - & - & \pm & - & - & \pm & - \\
\hline & $\%$ of $\mathrm{BrdU}+$ & - & \pm & - & - & \pm & - & 66.6 & \pm & 6.6 & 72.5 & \pm & 14.8 & 5.7 & \pm & 1.5 & 10.8 & \pm & 7.9 \\
\hline & abs. co-lab. & - & \pm & - & - & \pm & - & 1136.2 & \pm & 198.5 & 157.9 & \pm & $79.2^{* * *}$ & 107.0 & \pm & 30.1 & 29.7 & \pm & 18.4 \\
\hline \multirow[t]{4}{*}{ P260 } & & & $=4$ & & & $(n=$ & & & & & & & & & & & & & \\
\hline & BrdU abs. & 300.0 & \pm & 60.1 & 26.0 & \pm & $6.2^{* * *}$ & - & \pm & - & - & \pm & - & - & \pm & - & - & \pm & - \\
\hline & $\%$ of $\mathrm{BrdU}+$ & - & \pm & - & - & \pm & - & 49.7 & \pm & 2.0 & 44.4 & \pm & 29.4 & 9.1 & \pm & 3.2 & 5.6 & \pm & 5.6 \\
\hline & abs. co-lab. & - & \pm & - & - & \pm & - & 150.0 & \pm & 33.5 & 13.3 & \pm & $11.4^{* * *}$ & 30.1 & \pm & 15.4 & 0.7 & \pm & 0.7 \\
\hline
\end{tabular}


Table 2 Number of Ki67-positive cells and co-labeling with DCX

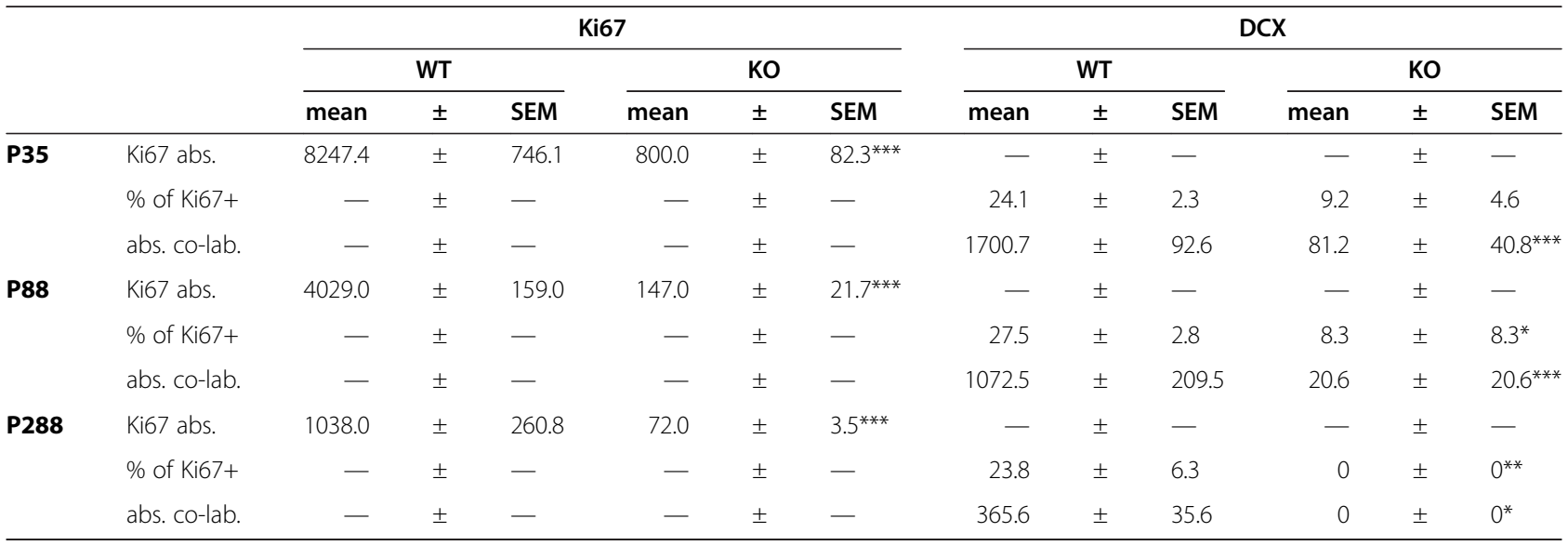

Two-way ANOVA followed by Holm-Sidak post hoc test $\left({ }^{*} p<0.05,{ }^{* *} p<0.01,{ }^{* * *} p<0.001 ;\right.$ cD2KO compared to WT); Abbreviations: abs. - absolute, abs. co-lab. absolute number of cells co-labeled with Ki67.

The number of granule neurons within the GCL was stereologically determined in mice aged P88 and P288. Estimations performed in WT mice were within the range reported in previous studies $[29,31,48,49]$.

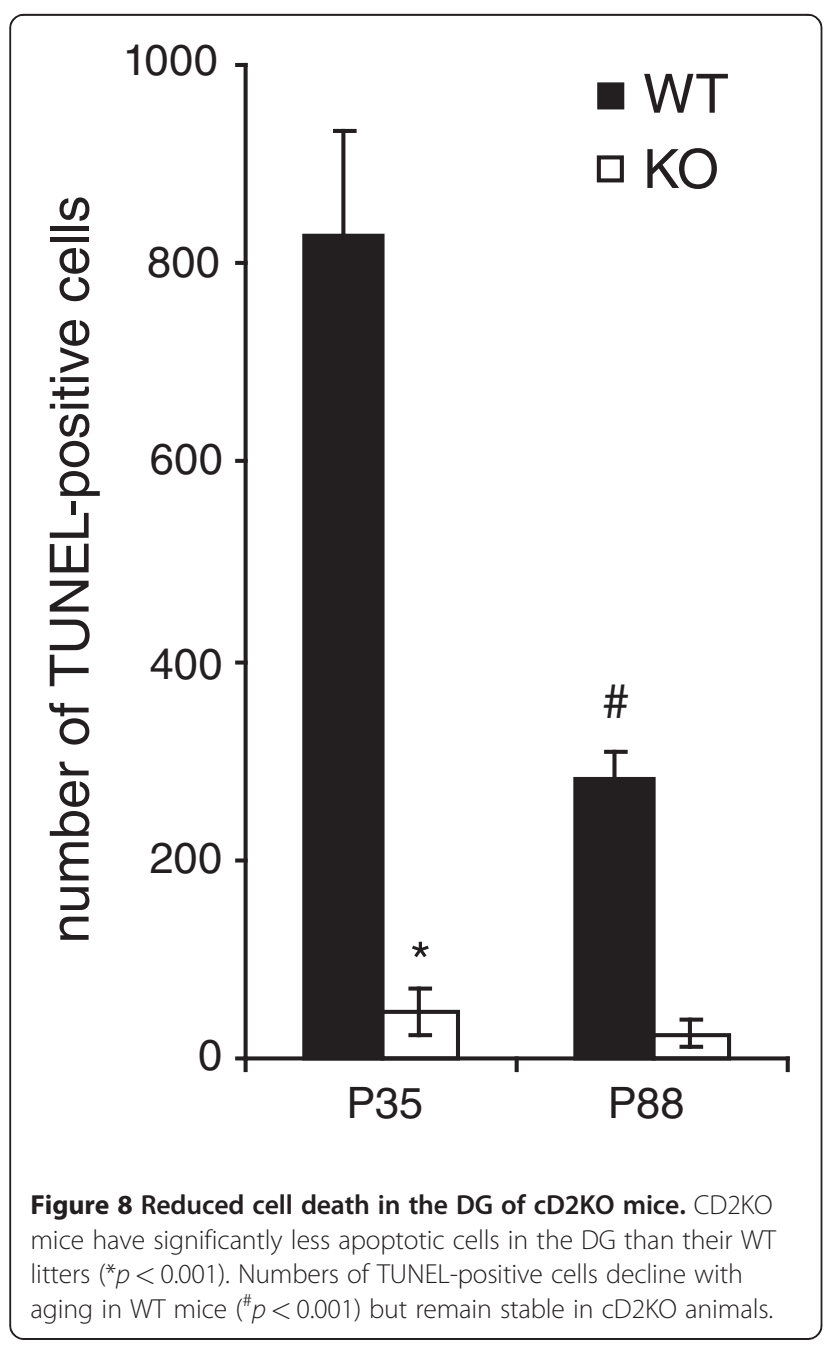

Similar as already shown for rats [50,51] and mice $[49,52]$, we observed a significant increase in the number of DGCs between P88 and P288. In contrast, DGC numbers were significantly reduced (at P88 to $40 \%$ and at P288 to $35 \%$ of WT, respectively) and did not change with age in $\mathrm{cD} 2 \mathrm{KO}$ mice. This indicates that though the lack of adult neurogenesis does not affect the number of neurons born earlier in life it prevents the age-related increase in DGC numbers. Thus, our results confirm previous reports suggesting that adult neurogenesis substantially adds new neurons to the hippocampal network rather than replacing existing neurons [49-51]. Further evaluation of the GCL revealed a significant volume reduction by $\sim 49 \%$ in cD2KO mice at all ages examined. There were no age-dependent differences detectable within the groups of $\mathrm{cD} 2 \mathrm{KO}$ and WT mice. Hence, while neurogenesis appears to be cumulative resulting in an increased number of DGCs over the lifetime of an animal, the volume of the DGL remains almost constant, irrespective of the presence or absence of adult neurogenesis. In agreement with previous studies $[49,50]$, this indicates that the density of DGCs in the mouse increases with age.

As during development, apoptotic cell death seems to play an important role in the regulation of the final number of newborn neurons in the neurogenic zones of the adult brain [53]. In WT mice, we observed TUNEL-positive, apoptotic cells at low frequencies throughout the DG. These cells preferentially resided in the SGZ, with few TUNEL-positive cells also found in the GCL. Analysis of WT mice revealed that numbers of dying cells in the DG decreased with age (P35 vs. P88). This was consistent with previous reports describing a continuous decline in cell death from 2 months onwards in mice [29], or between 2 and 6 weeks in rats [54]. In contrast, in cD2KO mice the number of dying cells in the DG was 
strongly reduced (by $>90 \%$ ) and showed no age-related decline. Thus, the pattern and numbers of TUNEL-positive cells closely correlate to that of newborn neurons in the DG. Even if these numbers are not directly comparable, they might be useful to illustrate the relationship between rates of cell birth and death: One-month (P35) old WT mice exhibit the highest rate of cell birth and death, with both features decreasing with age (i.e. between P35 and P88). Mice lacking cD2 have significantly less apoptotic cells than WT mice corresponding to their lower rate of cell birth. While these mice show no age-dependent decline in adult neurogenesis from P28 onwards, the numbers of apoptotic cells also appear to remain stable. These findings support previous reports suggesting that adult hippocampal neurogenesis is counterbalanced by the simultaneous elimination of newborn neurons through apoptosis [53].

\section{Conclusions}

The results of the present study emphasize the temporal dependency of hippocampal neurogenesis on $\mathrm{cD} 2$, and the importance of $\mathrm{cD} 2$ for adult neurogenesis. They suggest that postnatal neurogenesis is controlled by $\mathrm{cD} 2$ together with at least one other D-type cyclin. Hippocampal neurogenesis becomes increasingly dependent on cD2 during early postnatal development. Without functional cD2 it ceases at an age between P14 and P28, when the tertiary germinative matrix discontinues proliferative activity. These data indicate that $\mathrm{cD} 2$ becomes an essential requirement for ongoing neurogenesis with the transition from developmental to adult neurogenesis. Our data provide additional evidence that there is an ongoing, lifelong increase in the density of dentate granule cells due to adult neurogenesis.

Because of the lack of adult neurogenesis, cD2KO mice are a useful model to study the functional relevance of adult neurogenesis. In this context, our findings suggest that experimental interventions (such as physical activity, enriched environment, pharmacological treatments etc.) that interfere with hippocampal neurogenesis should not be started before neurogenesis becomes exclusively dependent on functional cD2.

\section{Methods}

\section{Mice}

All procedures involving living animals were carried out in strict compliance with the EC directive 86/609/EEC guidelines for animal experiments and were approved by the local government (Thueringer Landesamt, Bad Langensalza; permit no.: 02-012/07). Animals were housed under $12 \mathrm{~h}$ light/dark conditions with ad libitum access to food and water. The cyclin D2 gene was inactivated by excision of exons I and II [22]. Mice were kept as heterozygotes on $\mathrm{C} 57 \mathrm{Bl} / 6 \mathrm{~J}$ background. Homozygous cyclin
D2 knock out (cD2KO) and WT littermates ( $\mathrm{n} \geq 3$ as indicated in Table 1) were used for all experiments.

\section{BrdU injection and tissue processing}

Dividing cells were labeled by intraperitoneal injections of bromodeoxyuridine (BrdU, $50 \mathrm{mg} / \mathrm{kg}$ body weight; Sigma-Aldrich, St. Louis, MO, USA). Starting at either postnatal day (P) 7, P14, P28, P40, P60, P90, or P260, animals received BrdU every $8 \mathrm{~h}$ for 2 consecutive days (a total of 6 injections per animal; see Figure 1).

Twenty eight days thereafter, animals were deeply anesthetized and transcardially perfused with $4 \%$ paraformaldehyde in $0.1 \mathrm{M}$ phosphate buffer, $\mathrm{pH}$ 7.4. The brains were removed and post-fixed in the same fixative for $24 \mathrm{~h}$ at $4^{\circ} \mathrm{C}$. Thereafter brains were cryoprotected in $30 \% \mathrm{su}-$ crose (in $0.14 \mathrm{M} \mathrm{PBS}, 4^{\circ} \mathrm{C}$ ), frozen in 2-methylbutan $\left(-25\right.$ to $\left.-30^{\circ} \mathrm{C}\right)$ and stored at $-80^{\circ} \mathrm{C}$.

\section{Immunohistochemistry and -fluorescence}

Coronal sections $(40 \mu \mathrm{m})$ were treated for $30 \mathrm{~min}$ with $1.5 \% \mathrm{H}_{2} \mathrm{O}_{2}$, blocked in TBS plus, containing $0.1 \%$ triton, $2 \% \mathrm{BSA}$ and $3 \%$ donkey serum, and incubated over night at $4{ }^{\circ} \mathrm{C}$ with primary antibodies: rat $\alpha$-BrdU (1:500; AbD Serotec, Oxford, UK), rabbit $\alpha$-Ki67 (1:400; Novocastra, Newcastle, UK), or rabbit $\alpha$-cD1 (1:200; Thermo Fisher Scientific, Kalamazoo, MI, USA). Sections were then sequentially incubated in biotinylated secondary antibody (donkey $\alpha$-rat or donkey $\alpha$-rabbit, both 1:500; Dianova, Hamburg, Germany) for $3 \mathrm{~h}$ and Vectastain Elite ABC Kit (Vector Laboratories, Burlingame, CA, USA) for $1 \mathrm{~h}$, followed by DAB (3,3'-Diaminobenzidine tetrahydrochloride hydrate; Sigma-Aldrich) signal detection. For BrdU immunohistochemistry, a denaturation step (30 min $2 \mathrm{~N} \mathrm{HCl}$ ) followed by $10 \mathrm{~min}$ neutralization in $0.1 \mathrm{M}$ borate buffer pH 8.5 was included after $\mathrm{H}_{2} \mathrm{O}_{2}$ treatment. For cD1 epitope retrieval, sections were steamed for 15 min in citrate buffer $\mathrm{pH} 6$ before $\mathrm{H}_{2} \mathrm{O}_{2}$ treatment.

For immunofluorescence, a similar, but slightly modified protocol was applied: Briefly, to phenotype BrdU-positive cells, sections were pre-treated in TBS plus complemented with Fab $\alpha$-mouse (1:20; Dianova) and then rinsed and incubated with primary antibodies: rat $\alpha$ BrdU (1:500; AbD Serotec), mouse $\alpha-N e u N ~(1: 500 ;$ Millipore/Chemicon, Billerica, MA, USA), and rabbit $\alpha$-GFAP (1:1000; Synaptic Systems, Goettingen, Germany). To determine the phenotype of proliferating cells, sections were steamed for epitope retrieval (15 min in citrate buffer $\mathrm{pH}$ 6) and incubated with antibodies against Ki67 and doublecortin (goat $\alpha$-DCX, 1:100; Santa Cruz Biotechnology, Santa Cruz, CA, USA). As secondary antibodies we used: donkey $\alpha$-mouse Cy5, donkey $\alpha$-rabbit $\mathrm{RhX}$, donkey $\alpha$ goat Cy5 (1:250; all from Dianova), and goat $\alpha$-rat Alexa 
488 (1:250; Molecular Probes/Invitrogen, Carlsbad, CA, USA). Nuclei were counterstained with DAPI.

\section{TUNEL}

We used terminal deoxynucleotidyl transferase-mediated dUTP nick-end labeling (TUNEL) to detect nuclei with fragmented DNA, which is one of the hallmarks of latestate apoptosis. Every $24^{\text {th }} 40 \mu \mathrm{m}$-coronal section was rinsed in TBS and steamed for $15 \mathrm{~min}$ in $10 \mathrm{mM}$ sodium citrate buffer (pH6). After cooling, sections were permeabilized in TBS $/ 0.1 \%$ triton and incubated for $1 \mathrm{~h}$ at $37^{\circ} \mathrm{C}$ with the TUNEL reaction mixture containing $\mathrm{TdT}$ and TMRred-dUTP (Roche, Mannheim, Germany), followed by DAPI counterstaining to visualize nuclear profiles.

\section{Volumetric analyses}

Measurements were taken in every sixth $40 \mu \mathrm{m}$ coronal section stained with cresyl violet acetate (Sigma-Aldrich). Sections were digitized at appropriate magnification and the areas of the brain, the hippocampus and the dentate granule cell layer (GCL) were measured using Image software $(\mathrm{NIH})$. Volumes $(\mathrm{V})$ were calculated as $\mathrm{V}=\Sigma \mathrm{A}$ $\cdot i \cdot d$, according to Cavalieri's principle, with A representing the sum of areas from both hemispheres of each section, $i$ the interval between the sections, and $d$ the section thickness, respectively.

\section{Data quantification and statistical analysis}

Total numbers of BrdU- and Ki67-positive cells were counted in every $6^{\text {th }}$ section throughout the subgranular and granular cell layers of the entire DG using a Zeiss Axioplan 2 microscope (Carl Zeiss AG, Oberkochen, Germany). The resulting numbers were multiplied by 6 to obtain an estimate of the total numbers of BrdU-positive cells in the complete DG. A similar approach was applied for quantification of TUNEL-positive nuclei numbers.

For phenotyping of BrdU-positive cells, random fields of DG containing BrdU-positive cells were selected in every $12^{\text {th }}$ section and $\mathrm{z}$-stacks were scanned by confocal laser microscopy (LSM510, Zeiss). Phenotypes of 50-100 BrdU-positive cells per DG were determined in WT mice aged up to P90 and in cD2KO up to P14. BrdU-incorporation in the DG of cD2KO mice older than P14 and of P260 WT mice was sparse, hence the numbers of BrdUpositive cells that were phenotyped in these animals were less than 50. The percentage of co-labeled cells was calculated and absolute numbers were obtained by multiplying the percentage with the total numbers of BrdU-positive cells. A similar procedure was applied to study the co-localization of Ki67 and DCX.

Absolute numbers of DGCs were estimated stereologically (optical fractionator principle; StereoInvestigator, MBF Bioscience, Williston, USA; [55]) in a series of every $12^{\text {th }}$ DAPI-stained $40 \mu \mathrm{m}$-sections. For this purpose, a $70 \times 70 \mu \mathrm{m}$ grid was superimposed over each section and DGCs were counted in $10 \times 10 \mu \mathrm{m}$ counting frames using a 100x oil-immersion objective. Cells that were in sharp focus at the top and bottom (10\%) focal planes were disregarded to avoid over-sampling and bias due to tissue preparation artifacts. Total DGC number $(N)$ was calculated according to the equation $N=\Sigma Q^{-} \times$ $(1 / s s f) \times(1 / a s f) \times(1 / h s f)$, with $Q^{-}=$number of counts, $s s f=$ section sampling fraction, asf $=$ area sampling fraction, and $h s f=$ height sampling fraction (optical dissector height/average mounted section thickness). Calculation of the coefficient of error (CE) as estimator of accuracy of the probe runs was based on the Scheaffer method [56].

If not indicated otherwise, statistical comparisons were performed using 2-way ANOVA followed by Tukey test for multiple comparisons. In case the variables did not meet the assumptions for parametrical tests, data were $l n$ transformed before statistical testing. Data represent mean \pm SEM, $p$-values $<0.05$ were considered statistically significant.

\section{Additional file}

Additional file 1: Illustration of $\mathrm{CD} 1$ expression in the dentate gyrus of CD2KO and WT mice. CD1 positive cells were found scattered throughout the dentate gyrus of both, WT and CD2KO animals, with few CD1 positive cells located in the subgranular cell layer (arrowheads). The dashed line indicates the granule cell layer. Scale bar: $25 \mu \mathrm{m}$.

Competing interests

The authors declare that they have no competing interests.

\section{Acknowledgements}

We thank S. Beck for excellent technical assistance as well as L. Kaczmarek and R Filipkowski for kindly providing us with Cyclin D2 knock out mice for breeding. We also thank N. Kroegel and C. Schmeer for careful language editing of the manuscript.

This work was funded by the Federal Ministry of Education and Research (BMBF, http://www.bmbf.de; grant no. 01GZ0709) and the National Bernstein Network Computational Neuroscience (http://www. nncn.uni-freiburg.de; grant no.01GQ0923). A. Urbach was supported by the Interdisciplinary Center for Clinical Research Jena (http://www.izkf. uk-j.de; IZKF/J15). The funders had no role in study design, data collection and analysis, decision to publish, or preparation of the manuscript.

\section{Authors' contributions}

AA performed immunohistochemistry, confocal analyses and cell countings and participated in data analysis and manuscript preparation. AU conceived and designed the experiments, carried out the TUNEL analysis and granule cell quantification, participated in data analysis and interpretation, and wrote the manuscript. OWW participated in study design and revised the manuscript. All authors read and approved the final manuscript.

Received: 8 November 2011 Accepted: 7 May 2012

Published: 7 May 2012

\section{References}

1. Balu DT, Lucki I: Adult hippocampal neurogenesis: Regulation, functional implications, and contribution to disease pathology. Neurosci Biobehav Rev 2008, 2008:2008. 
2. Deng W, Saxe MD, Gallina IS, Gage FH: Adult-born hippocampal dentate granule cells undergoing maturation modulate learning and memory in the brain. J Neurosci 2009, 29(43):13532-13542.

3. Ge S, Sailor KA, Ming GL, Song H: Synaptic integration and plasticity of new neurons in the adult hippocampus. J Physio/ 2008, 586(16):3759-3765.

4. Song H, Kempermann G, Overstreet Wadiche L, Zhao C, Schinder AF, Bischofberger J: New neurons in the adult mammalian brain: synaptogenesis and functional integration. J Neurosci 2005, 25(45):10366-10368.

5. Ge S, Yang $\mathrm{CH}$, Hsu KS, Ming GL, Song H: A critical period for enhanced synaptic plasticity in newly generated neurons of the adult brain. Neuron 2007, 54(4):559-566.

6. Mongiat LA, Schinder AF: Adult neurogenesis and the plasticity of the dentate gyrus network. Eur J Neurosci 2011, 33(6):1055-1061.

7. Matsushime H, Ewen ME, Strom DK, Kato JY, Hanks SK, Roussel MF, Sherr CJ: Identification and properties of an atypical catalytic subunit (p34PSK-J3/ cdk4) for mammalian D type G1 cyclins. Cell 1992, 71(2):323-334.

8. Meyerson M, Harlow E: Identification of G1 kinase activity for cdk6, a novel cyclin D partner. Mol Cell Biol 1994, 14(3):2077-2086.

9. Sherr CJ: Growth factor-regulated G1 cyclins. Stem Cells 1994, 12:47-55.

10. Matsushime H, Quelle DE, Shurtleff SA, Shibuya M, Sherr CJ, Kato JY: D-type cyclin-dependent kinase activity in mammalian cells. Mol Cell Biol 1994, 14(3):2066-2076.

11. Assoian RK, Zhu X: Cell anchorage and the cytoskeleton as partners in growth factor dependent cell cycle progression. Curr Opin Cell Biol 1997, 9(1):93-98.

12. Lukas J, Bartkova J, Welcker M, Petersen OW, Peters G, Strauss M, Bartek J: Cyclin D2 is a moderately oscillating nucleoprotein required for $\mathrm{G} 1$ phase progression in specific cell types. Oncogene 1995, 10(11):2125-2134.

13. Matsushime H, Roussel MF, Ashmun RA, Sherr CJ: Colony-stimulating factor 1 regulates novel cyclins during the G1 phase of the cell cycle. Cell 1991, 65(4):701-713

14. Aguzzi A, Kiess M, Rüedi D, Hamel PA: Cyclins D1, D2 and D3 are expressed in distinct tissues during mouse embryogenesis. Transgenics 1996, 2:29-39.

15. Wianny F, Real FX, Mummery CL, Van Rooijen M, Lahti J, Samarut J, Savatier P: G1-phase regulators, cyclin D1, cyclin D2, and cyclin D3: up-regulation at gastrulation and dynamic expression during neurulation. Dev Dyn 1998, 212(1):49-62.

16. Sherr CJ, Roberts JM: Living with or without cyclins and cyclin-dependent kinases. Genes Dev 2004, 18(22):2699-2711.

17. Chen B, Pollard JW: Cyclin D2 compensates for the loss of cyclin D1 in estrogen-induced mouse uterine epithelial cell proliferation. $\mathrm{Mol}$ Endocrinol 2003, 17(7):1368-1381.

18. Ciemerych MA, Kenney AM, Sicinska E, Kalaszczynska I, Bronson RT, Rowitch DH, Gardner H, Sicinski P: Development of mice expressing a single Dtype cyclin. Genes Dev 2002, 16(24):3277-3289.

19. Fantl V, Stamp G, Andrews A, Rosewell I, Dickson C: Mice lacking cyclin D1 are small and show defects in eye and mammary gland development. Genes Dev 1995, 9(19):2364-2372.

20. Kozar K, Ciemerych MA, Rebel VI, Shigematsu H, Zagozdzon A, Sicinska E, Geng Y, Yu Q, Bhattacharya S, Bronson RT, et al: Mouse development and cell proliferation in the absence of D-cyclins. Cell 2004, 118(4):477-491.

21. Lam EW, Glassford J, Banerji L, Thomas NS, Sicinski P, Klaus GG: Cyclin D3 compensates for loss of cyclin D2 in mouse B-lymphocytes activated via the antigen receptor and CD40. J Biol Chem 2000, 275(5):3479-3484.

22. Sicinski P, Donaher JL, Geng Y, Parker SB, Gardner H, Park MY, Robker RL, Richards JS, McGinnis LK, Biggers JD, et al: Cyclin D2 is an FSH-responsive gene involved in gonadal cell proliferation and oncogenesis. Nature 1996, 384(6608):470-474.

23. Sicinski P, Donaher JL, Parker SB, Li T, Fazeli A, Gardner H, Haslam SZ, Bronson RT, Elledge SJ, Weinberg RA: Cyclin D1 provides a link between development and oncogenesis in the retina and breast. Cell 1995, 82(4):621-630.

24. Huard JM, Forster CC, Carter ML, Sicinski P, Ross ME: Cerebellar histogenesis is disturbed in mice lacking cyclin D2. Development 1999, 126(9):1927-1935.

25. Sicinska E, Aifantis I, Le Cam L, Swat W, Borowski C, Yu Q, Ferrando AA, Levin SD, Geng $Y$, von Boehmer $H$, et al: Requirement for cyclin D3 in lymphocyte development and T cell leukemias. Cancer Cell 2003, 4(6):451-461.

26. Solvason N, Wu WW, Parry D, Mahony D, Lam EW, Glassford J, Klaus GG, Sicinski P, Weinberg R, Liu YJ, et al: Cyclin D2 is essential for BCR-mediated proliferation and CD5 B cell development. Int Immunol 2000, 12(5):631-638.

27. Kowalczyk A, Filipkowski RK, Rylski M, Wilczynski GM, Konopacki FA, Jaworski J, Ciemerych MA, Sicinski P, Kaczmarek L: The critical role of cyclin D2 in adult neurogenesis. J Cell Biol 2004, 167(2):209-213.
28. Amrein I, Slomianka L, Poletaeva II, Bologova NV, Lipp HP: Marked species and age-dependent differences in cell proliferation and neurogenesis in the hippocampus of wild-living rodents. Hippocampus 2004, 14(8):1000-1010.

29. Ben Abdallah NM, Slomianka L, Vyssotski AL, Lipp HP: Early age-related changes in adult hippocampal neurogenesis in C57 mice. Neurobiol Aging 2010, 31(1):151-161.

30. Bondolfi L, Ermini F, Long JM, Ingram DK, Jucker M: Impact of age and caloric restriction on neurogenesis in the dentate gyrus of $\mathrm{C} 57 \mathrm{BL} / 6$ mice. Neurobiol Aging 2004, 25(3):333-340.

31. Kempermann G, Kuhn HG, Gage FH: Experience-induced neurogenesis in the senescent dentate gyrus. J Neurosci 1998, 18(9):3206-3212.

32. Kronenberg G, Bick-Sander A, Bunk E, Wolf C, Ehninger D, Kempermann G: Physical exercise prevents age-related decline in precursor cell activity in the mouse dentate gyrus. Neurobiol Aging 2006, 27(10):1505-1513.

33. Zhao C, Deng W, Gage FH: Mechanisms and functional implications of adult neurogenesis. Cell 2008, 132(4):645-660.

34. Amrein I, Isler K, Lipp HP: Comparing adult hippocampal neurogenesis in mammalian species and orders: influence of chronological age and life history stage. Eur J Neurosci 2011, 34(6):978-987.

35. Harrist A, Beech RD, King SL, Zanardi A, Cleary MA, Caldarone BJ, Eisch A, Zoli M, Picciotto MR: Alteration of hippocampal cell proliferation in mice lacking the beta 2 subunit of the neuronal nicotinic acetylcholine receptor. Synapse 2004, 54(4):200-206.

36. Kee N, Sivalingam S, Boonstra R, Wojtowicz JM: The utility of Ki-67 and $\mathrm{BrdU}$ as proliferative markers of adult neurogenesis. J Neurosci Methods 2002, 115(1):97-105

37. Mandyam CD, Harburg GC, Eisch AJ: Determination of key aspects of precursor cell proliferation, cell cycle length and kinetics in the adult mouse subgranular zone. Neuroscience 2007, 146(1):108-122.

38. Angevine JB Jr: Time of neuron origin in the hippocampal region An autoradiographic study in the mouse. Exp Neurol 1965, Suppl 2:1-70.

39. Altman J, Bayer SA: Migration and distribution of two populations of hippocampal granule cell precursors during the perinatal and postnatal periods. J Comp Neurol 1990, 301(3):365-381.

40. Altman J, Bayer SA: Mosaic organization of the hippocampal neuroepithelium and the multiple germinal sources of dentate granule cells. J Comp Neurol 1990, 301(3):325-342.

41. Bayer SA: Development of the hippocampal region in the rat. II. Morphogenesis during embryonic and early postnatal life. J Comp Neurol 1980, 190(1):115-134.

42. Glickstein SB, Alexander S, Ross ME: Differences in cyclin D2 and D1 protein expression distinguish forebrain progenitor subsets. Cereb Cortex 2007, 17(3):632-642.

43. McDonald HY, Wojtowicz JM: Dynamics of neurogenesis in the dentate gyrus of adult rats. Neurosci Lett 2005, 385(1):70-75.

44. Steiner B, Klempin F, Wang L, Kott M, Kettenmann H, Kempermann G: Type-2 cells as link between glial and neuronal lineage in adult hippocampal neurogenesis. GLIA 2006, 54(8):805-814.

45. Kronenberg G, Reuter K, Steiner B, Brandt MD, Jessberger S, Yamaguchi M, Kempermann G: Subpopulations of proliferating cells of the adult hippocampus respond differently to physiologic neurogenic stimuli. J Comp Neurol 2003, 467(4):455-463.

46. Kempermann G, Jessberger S, Steiner B, Kronenberg G: Milestones of neuronal development in the adult hippocampus. Trends Neurosci 2004, 27(8):447-452.

47. Rao MS, Hattiangady B, Abdel-Rahman A, Stanley DP, Shetty AK: Newly born cells in the ageing dentate gyrus display normal migration, survival and neuronal fate choice but endure retarded early maturation. Eur I Neurosci 2005, 21(2):464-476.

48. Amrein I, Slomianka L, Lipp HP: Granule cell number, cell death and cell proliferation in the dentate gyrus of wild-living rodents. Eur J Neurosci 2004, 20(12):3342-3350.

49. Imayoshi I, Sakamoto M, Ohtsuka T, Takao K, Miyakawa T, Yamaguchi M, Mori K, Ikeda T, Itohara S, Kageyama R: Roles of continuous neurogenesis in the structural and functional integrity of the adult forebrain. Nat Neurosci 2008, 11:1153-1161.

50. Bayer SA, Yackel JW, Puri PS: Neurons in the rat dentate gyrus granular layer substantially increase during juvenile and adult life. Science 1982 216(4548):890-892 
51. Crespo D, Stanfield BB, Cowan WM: Evidence that late-generated granule cells do not simply replace earlier formed neurons in the rat dentate gyrus. Exp Brain Res 1986, 62(3):541-548.

52. Wimer RE, Wimer CC, Alameddine L: On the development of strain and sex differences in granule cell number in the area dentata of house mice. Brain Res 1988, 470(2):191-197.

53. Biebl M, Cooper CM, Winkler J, Kuhn HG: Analysis of neurogenesis and programmed cell death reveals a self-renewing capacity in the adult rat brain. Neurosci Lett 2000, 291(1):17-20.

54. Heine VM, Maslam S, Joels M, Lucassen PJ: Prominent decline of newborn cell proliferation, differentiation, and apoptosis in the aging dentate gyrus, in absence of an age-related hypothalamus-pituitary-adrenal axis activation. Neurobiol Aging 2004, 25(3):361-375.

55. West MJ, Slomianka L, Gundersen HJ: Unbiased stereological estimation of the total number of neurons in the subdivisions of the rat hippocampus using the optical fractionator. Anat Rec 1991, 231(4):482-497.

56. Scheaffer RL, Mendenhall W, Ott L: Elementary Survey Sampling (Statistics). 5th edition. Pacific Grove: Duxbury Press; 1995.

doi:10.1186/1471-2202-13-46

Cite this article as: Ansorg et al:: Age-dependent kinetics of dentate gyrus neurogenesis in the absence of cyclin D2. BMC Neuroscience 2012 13:46.

\section{Submit your next manuscript to BioMed Central and take full advantage of:}

- Convenient online submission

- Thorough peer review

- No space constraints or color figure charges

- Immediate publication on acceptance

- Inclusion in PubMed, CAS, Scopus and Google Scholar

- Research which is freely available for redistribution 